\section{RSP}

http://www.rsp.fsp.usp.br/
Revista de Saúde Pública

\title{
ERICA: prevalence of metabolic syndrome in Brazilian adolescents
}

\author{
Maria Cristina C Kuschnir', Katia Vergetti Bloch", Moyses Szklo", Carlos Henrique Klein"', Laura \\ Augusta Barufaldi", Gabriela de Azevedo Abreu"v, Beatriz Schaanv, Gloria Valeria da Veigav", Thiago \\ Luiz Nogueira da Silva", Maurício T L de Vasconcellos ${ }^{\mathrm{VII}}$ and other authors*
}

I Faculdade de Ciências Médicas. Núcleo de Estudos da Saúde do Adolescente. Universidade do Estado do Rio de Janeiro. Rio de Janeiro, RJ, Brasil

" Instituto de Estudos em Saúde Coletiva. Universidade Federal do Rio de Janeiro. Rio de Janeiro, RJ, Brasil

III Escola Nacional de Saúde Pública. Fundação Oswaldo Cruz. Rio de Janeiro, RJ, Brasil

Iv Programa de Pós-Graduação em Saúde Coletiva. Instituto de Medicina Social. Universidade do Estado do Rio de Janeiro. Rio de Janeiro. RJ Brasil

v Hospital de Clínicas de Porto Alegre. Universidade Federal do Rio Grande do Sul. Porto Alegre, RS, Brasil

Vı Instituto de Nutrição Josué de Castro. Universidade Federal do Rio de Janeiro. Rio de Janeiro, RJ, Brasil

VII Escola Nacional de Ciências Estatísticas. Fundaçãoa Instituto Brasileiro de Geografia e Estatística. Rio de Janeiro, RJ, Brasil

\section{ABSTRACT}

OBJECTIVE: To determine the prevalence of metabolic syndrome and its components in Brazilian adolescents.

METHODS: We evaluated 37,504 adolescents who were participants in the Study of Cardiovascular Risks in Adolescents (ERICA), a cross-sectional, school-based, national study. The adolescents, aged from 12 to 17 years, lived in cities with populations greater than 100,000 inhabitants. The sample was stratified and clustered into schools and classes. The criteria set out by the International Diabetes Federation were used to define metabolic syndrome. Prevalences of metabolic syndrome were estimated according to sex, age group, school type and nutritional status.

Correspondence:

Maria Cristina C. Kuschnir Rua Álvaro Ramos, 405 apto 608, Bloco 2, Botafogo

22280-110 Rio de Janeiro, RJ, Brasil E-mail: cristina.kuschnir@gmail.com

Received: 20 Sep 2015

Approved: 4 Nov 2015

How to cite: Kuschnir MCC Bloch KV, Szklo M, Klein CH, Barufaldi LA, Abreu GA et al. ERICA: prevalência de síndrome metabólica em adolescentes brasileiros. Rev Saude Publica. 2016:50(supl 1):11s.

Copyright: This is an open-access article distributed under the terms of the Creative Commons Attribution License, which permits unrestricted use, distribution, and reproduction in any medium, provided that the original author and source are credited.

RESULTS: Of the 37,504 adolescents who were evaluated: $50.2 \%$ were female; $54.3 \%$ were aged from 15 to 17 years, and $73.3 \%$ were from public schools. The prevalence of metabolic syndrome was $2.6 \%$ (95\%CI 2.3-2.9), slightly higher in males and in those aged from 15 to 17 years in most macro-regions. The prevalence was the highest in residents from the South macro-region, in the younger female adolescents and in the older male adolescents. The prevalence was higher in public schools (2.8\% [95\%CI 2.4-3.2]), when compared with private schools (1.9\% [95\%CI 1.4-2.4]) and higher in obese adolescents when compared with nonobese ones. The most common combinations of components, referring to 3/4 of combinations, were: enlarged waist circumference (WC), low HDL-cholesterol (HDL-c) and high blood pressure; followed by enlarged WC, low HDL-c and high triglycerides; and enlarged WC, low HDL-c, high triglycerides and blood pressure. Low HDL was the second most frequent component, but the highest prevalence of metabolic syndrome (26.8\%) was observed in the presence of high triglycerides.

CONCLUSIONS: ERICA is the first Brazilian nation-wide study to present the prevalence of metabolic syndrome and describe the role of its components. Despite the prevalence of Metabolic Syndrome being low, the high prevalences of some components and participation of others in the syndrome composition shows the importance of early diagnosis of this changes, even if not grouped within the metabolic syndrome.

DESCRIPTORS: Adolescent. Metabolic Syndrome, epidemiology. Risk Factors. Cardiovascular Diseases. Cross-Sectional Studies. 


\section{INTRODUCTION}

The increasing prevalence of overweight and obese children and adolescents, which has been observed in several countries ${ }^{18}$, including Brazil ${ }^{15}$, represent a serious public health problem in terms of the various health risks that obesity can cause, both during adolescence and adult life. Included among the already recognized cardiovascular risk factors are those that make up the so-called metabolic syndrome (MS). The following are associated with MS: enlarged waist circumference (WC), low levels of high-density lipoprotein cholesterol (HDL-c), high systemic blood pressure, high triglycerides, and high blood glucose. An individual is positively diagnosed with MS if he/she has at least three of these conditions, which are related to cardiovascular disease and can have it as one of the adverse outcomes ${ }^{24}$.

Various proposals are set out to define MS in children and adolescents. However, no consensus exists on what their components or cut-off points would be, which have already been defined for adults. In 2004, Ferranti et al. ${ }^{10}$ proposed an adaptation of the criteria created by the National Cholesterol Education Program Adult Treatment Panel (NCEP-ATPIII). According to this MS definition, the cut-off point for $\mathrm{WC}$ is the $70^{\text {th }}$ percentile ${ }^{10}$.

In 2007, the International Diabetes Federation (IDF) established a new concept for defining MS in children and adolescents. This concept considers increased WC measurement as the main component for defining MS. Thus, MS became being diagnosed in children aged 10 years or more when their WC was greater than or equal to the $90^{\text {th }}$ percentile of the curve developed by Fernandez et al. ${ }^{9}$, and at the same time, presenting two or more of the clinical or laboratory criteria (low HDL-c and high blood pressure, triglycerides and high glucose). For adolescents aged over 16 years, the adult IDF criteria are used ${ }^{25}$. In 2014, Giannini et al. ${ }^{12}$ observed that using the IDF criteria resulted in lower prevalences in a sample of overweight adolescents when compared with the NCEP-ATPIII criteria. Tavares et al. ${ }^{22}$, during a systematic review of 15 articles performed with Brazilian adolescents, 11 of which are in the Southeast region, observed a variation of between $0 \%$ and $42.0 \%$ in MS prevalence, which depended on the diagnostic criteria used, being more pronounced in overweight individuals.

The objective of this study was to determine the prevalence of MS in Brazilian adolescents.

\section{METHODS}

The Estudo de Riscos Cardiovasculares em Adolescentes (ERICA - Study of Cardiovascular Risk in Adolescents) was designed to estimate the prevalence of cardiovascular risk factors that make up MS in a representative sample of adolescents aged from 12 to 17 years. The selected adolescents were attending the seventh, eighth and ninth year of elementary school or the first, second or third year of high school, in public or private schools, studied in the morning shift and lived in Brazilian cities with populations higher than 100,000 inhabitants. These school years weres chosen to include the largest possible number of adolescents aged from 12 to 17 years, since no information base exists regarding individual adolescent units for a sample selection, but only combinations of classes and years at the schools.

The sample was stratified into 32 strata, made up of the 27 Brazilian state capital cities and five sets of the other countryside cities, with more than 100,000 inhabitants, from each of the five macro-regions of Brazil. Thus, the sample is representative for medium- and large-sized cities at the regional and national level and for the capitals and the Federal District. Clusters were selected at three levels: schools, combinations of year and shift, and classes. The sampling weights were calculated by the product of the inverse probability of inclusion at each stage of the sample selection and were calibrated considering the estimates of the adolescent population enrolled in schools located in the geographic strata based on sex and age. The analysis was adjusted to account for the sample design, which was done using statistical routines for a complex sampling that considers the sources of variability and calibration with population estimates. 
The sample size calculation considered an expected MS prevalence of $4.0 \%$ in adolescents 6 , with a maximum error level of $0.9 \%$ and a $95 \%$ confidence level, as well as a 2.97 agglomeration effect. A detailed description of the sampling process can be seen in Vasconcellos et al. ${ }^{23}$

To estimate the prevalence of MS, biochemical analyses were performed in the plasma. The fasting time required for blood collection was 12 hours, and therefore was only done with the morning shift students who were selected in the ERICA sample. Thus, any inference from the results regarding MS can only be made for students who attend the morning shift.

The sex and age variables were obtained through a self-filled questionnaire that was completed by the respondent on an electronic data collector (PDA) which also contained other questions not used in this analysis. The age variable was confirmed using school records. The following anthropometrical variables were measured by trained researchers: WC, measurement of the circumference of the right arm ( for choosing the appropriate cuff for measuring blood pressure), weight and height. These measurements were monitored throughout the collection by means of a quality control that verified their limits and distribution of digits.

Weight was evaluated using a P200M Líder ${ }^{\circledR}$ scale, which has a capacity of up to $200 \mathrm{~kg}$ and a $50 \mathrm{~g}$ variation. Height was measured twice using an Altura Exata ${ }^{\circledR}$ portable stadiometer with a 0.1 variation, with the mean of the two values obtained being the value taken into consideration. The weight and height measurements were used to classify the nutritional status, based on the body mass index calculation $\left(\mathrm{BMI}=\right.$ weight $/$ height $\left.^{2}\right)$. Classifying the nutritional status involved using the BMI curves as proposed by the World Health Organization ${ }^{17}(2007)$ specified by age and sex. Adolescents considered to have an adequate nutritional status had a score of $+1>Z \geq-2$, overweight adolescents had a score of $+2>Z \geq+1$, and obese adolescents were those with a $Z \geq+2$ score.

WC was measured using a Sanny ${ }^{\circledR}$ inelastic measuring tape, which had $0.1 \mathrm{~cm}$ variation, at the midpoint between the bottom of the last rib and the upper curvature of the iliac crest, with the adolescent in a standing position, arms along the body and with his/her feet and abdomen relaxed.

Blood pressure was measured using a Omron ${ }^{\circledR} 705$-IT, machine, which had been validated for use in adolescents ${ }^{21}$. Three blood pressure measurements were taken, with the mean of the final two being used in the hypertension classification. Systemic blood pressure was considered high if the systolic blood pressure was greater than or equal to $130 \mathrm{mmHg}$, and the diastolic blood pressure was greater than or equal to $85 \mathrm{mmHg}$.

Blood sample analyses of biochemical parameters that are included in MS (HDL-c, triglycerides and glucose) were performed in only one laboratory that followed the current required quality standards for its qualification. Fasting blood glucose was analyzed with the GOD-PAP enzymatic method in the Roche modular analytical equipment. Values of $100 \mathrm{mg} / \mathrm{dL}$ or more were considered as discriminants of high blood glucose $\mathrm{e}^{2}$. Triglycerides and HDL-c were analyzed with the enzymatic colorimetric method using Roche modular analytical equipment. Reference values published in I Guidelines of Prevention of Atherosclerosis during Childhood and Adolescence were used ${ }^{20}$. A full description of the ERICA methods can be found in Bloch et al. ${ }^{4}$

A positive MS classification was given when at least three of the below components were present, with a mandatory requirement for enlarged WC, which is in accordance with the criteria from the International Diabetes Federation²:

- WC

$<16$ years: $\geq 90^{\text {th }}$ percentile

$\geq 16$ years, male: $\geq 90 \mathrm{~cm}$

$\geq 16$ years, male: $\geq 80 \mathrm{~cm}$ 
- HDL-c

$<16$ years: $40 \mathrm{mg} / \mathrm{dL}$

$\geq 16$ years, male: $<40 \mathrm{mg} / \mathrm{dL}$

$\geq 16$ years, female: $<50 \mathrm{mg} / \mathrm{dL}$

- Triglycerides: $\geq 150 \mathrm{mg} / \mathrm{dL}$

- Glucose: $\geq 100 \mathrm{mg} / \mathrm{dL}$

- Systolic blood pressure $\geq 130 \mathrm{mmHg}$ or diastolic blood pressure $\geq 85 \mathrm{mmHg}$

Adolescents who had any disability that would prevent weight, height and WC from being evaluated were excluded from this study. Pregnant women were also excluded.

Prevalences of MS were estimated with their respective 95\% confidence intervals (95\%CI) in the strata corresponding to the Brazilian macro-regions, according to sex and age groups, from 12 to 14 and 15 to 17 years of age. The complex sample design was taken into account, with weighting included due to the different probabilities of cluster selection and subsequent calibration by age and sex, from which the population estimates were obtained ${ }^{a}$. The prevalences of MS were also estimated by the schools' status (public or private), in obese and nonobese adolescents, as were the risk factors that make up the IDF criterion for MS. Statab ${ }^{\mathrm{b}}$ software 14 version was used for data analysis.

ERICA was approved by the Committee for Ethics in Research (CEP) of the Institute of Collective Health Studies, Universidade Federal do Rio de Janeiro (Process 45/2008) and by a CEP of each unit of the Federation. The adolescents who participated in this study agreed in writing to participate and their legal guardians signed an informed consent form.

\section{RESULTS}

Figure 1 presents a flow chart of the participants. We evaluated 37,504 adolescents, of which $60.0 \%$ were female, $54.3 \%$ were aged between 15 to 17 years and $73.3 \%$ studied in public schools.

a Instituto Brasileiro de Geografia e Estatística. Projeção da população do Brasil por sexo e idade - 1980-2050: revisão 2008. Rio de Janeiro (RJ): IBGE; 2008 [cited 2015 Sept]. (Estudos e pesquisas, 24). Available from: http://www.ibge.gov.br/home/ estatistica/populacao/projecao_ da_populacao/2008/projecao.pdf

${ }^{\mathrm{b}}$ Stata Corp. Stata statistical software: release 14 . College Station, Texas; 2015.

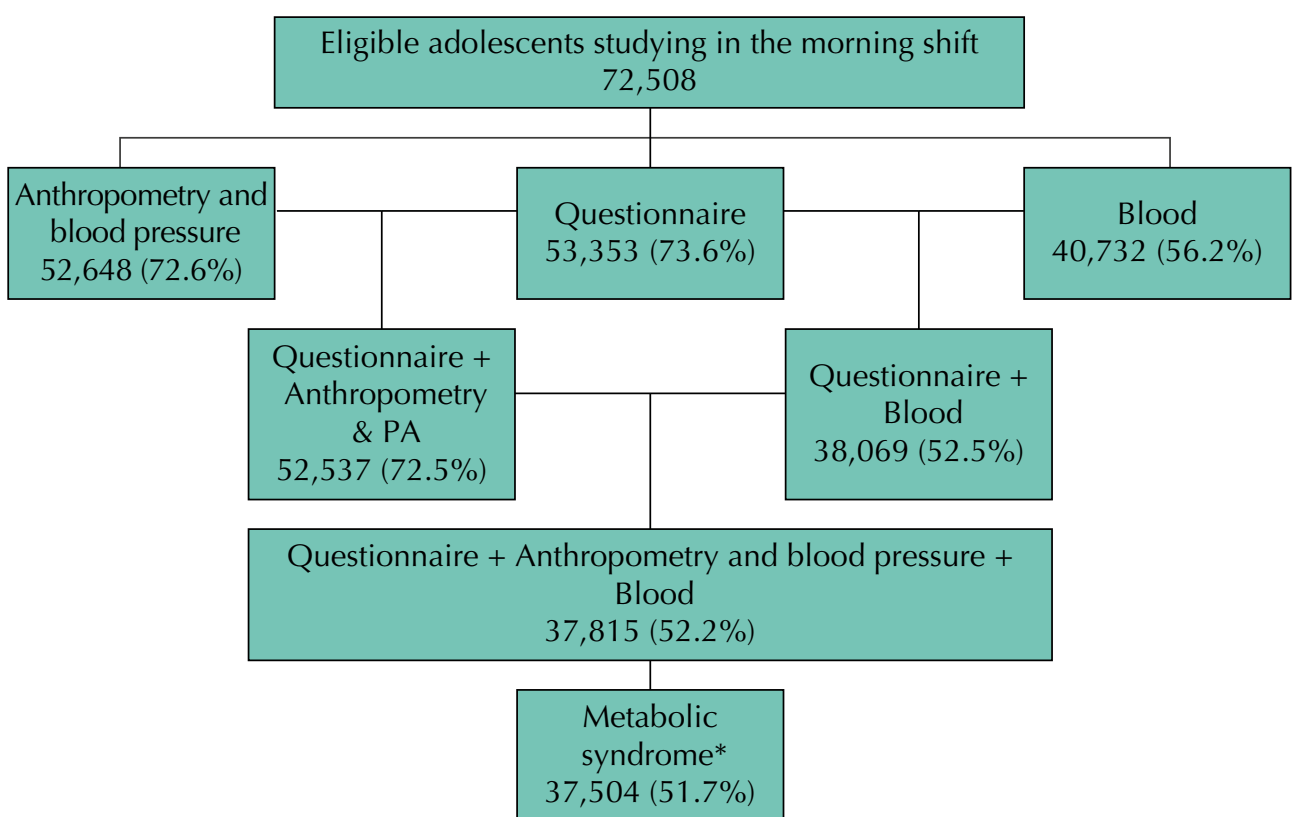

* 311 adolescents did not have results from all the tests required for diagnosing metabolic syndrome.

Figure 1. Flowchart of the participants assessed regarding the prevalence of metabolic syndrome. ERICA, Brazil, 2013-2014. 
The prevalence of MS in schools in Brazilian cities with more than 100,000 inhabitants, for students studying in the morning, is presented in Table 1. Regarding the prevalence of MS by sex and age group, small variations occurred in the prevalence with an overlapping of the $95 \%$ confidence interval (Table 2). In relation to age group, in most regions the prevalence was higher in adolescents aged between 15 and 17 years. However, in the South region, the prevalence of MS in adolescents aged between 12 and 17 years was greater than in those between 15 and 17 years, albeit with an overlapping of the confidence intervals; for male adolescents the opposite occurred together with statistical significance. In the Midwest region, younger male adolescents showed greater MS prevalence than the older age group, from 15 to 17 years of age.

The Brazilian state capital that presented the highest MS prevalence was Belem (3.8\% [95\%CI 2.7-5.2]), with the smallest being Macapa (0.9\% [95\%CI 0.3-2.7]), which are both in the North region and had the largest variations between them (Figure 2). However, when all the strata

Table 1. Prevalences (\%) and $95 \% \mathrm{Cl}$ of metabolic syndrome, sample size and estimated population in the set of cities with more than 100,000 inhabitants in Brazil, according to sex and age group. ERICA, 2013-2014.

\begin{tabular}{lccccc}
\hline Characteristic & Age group & Sample & Population & $\%$ & $\mathbf{9 5 \%} \mathbf{C l}$ \\
\hline Female & $12-14$ & 10,134 & $1,536,757$ & 2.5 & $1.7-3.6$ \\
& $15-17$ & 12,365 & $1,788,116$ & 2.1 & $1.5-2.7$ \\
\multirow{3}{*}{ Male } & $12-17$ & 22,499 & $3,324,873$ & 2.2 & $1.8-2.8$ \\
& $12-14$ & 7,016 & $1,552,255$ & 2.5 & $2.0-3.2$ \\
& $15-17$ & 7,990 & $1,751,833$ & 3.3 & $2.5-4.2$ \\
Brazil & $12-17$ & 15,006 & $3,304,088$ & 2.9 & $2.5-3.4$ \\
& $12-14$ & 17,150 & $3,089,012$ & 2.5 & $2.0-3.0$ \\
& $15-17$ & 20.355 & $3,539,949$ & 2.7 & $2.2-3.2$ \\
& $12-17$ & 37,504 & $6,628,961$ & 2.6 & $2.3-2.9$ \\
\hline
\end{tabular}

Table 2. Prevalences (\%) and $95 \% \mathrm{Cl}$ of metabolic syndrome, sample size and estimated population in cities with more than 100,000 inhabitants, according to Brazilian regions, sex and age group. ERICA, 2013-2014.

\begin{tabular}{|c|c|c|c|c|c|}
\hline Regions/Sex & Age group & Sample & Population & $\%$ & $95 \% \mathrm{Cl}$ \\
\hline North & & 7,233 & 456,416 & 2.3 & $2.0-2.8$ \\
\hline \multirow[t]{2}{*}{ Female } & $12-14$ & 1,979 & 126,869 & 2.0 & $1.3-3.0$ \\
\hline & $15-17$ & 2,279 & 100,881 & 2.5 & $1.8-3.4$ \\
\hline \multirow[t]{2}{*}{ Male } & $12-14$ & 1,458 & 127,856 & 1.6 & $0.9-2.8$ \\
\hline & $15-17$ & 1,517 & 100,810 & 3.5 & $2.6-4.7$ \\
\hline Northeast & & 11,661 & $1,337,676$ & 2.7 & $2.3-3.1$ \\
\hline \multirow[t]{2}{*}{ Female } & $12-14$ & 3,314 & 343,871 & 2.2 & $1.3-4.0$ \\
\hline & $15-17$ & 3,722 & 325,047 & 2.3 & $1.7-3.3$ \\
\hline \multirow[t]{2}{*}{ Male } & $12-14$ & 2,160 & 350,923 & 2.7 & $1.8-4.1$ \\
\hline & $15-17$ & 2,465 & 317,835 & 3.4 & $2.6-4.4$ \\
\hline Midwest & & 5,441 & 525,340 & 2.2 & $1.7-3.0$ \\
\hline \multirow[t]{2}{*}{ Female } & $12-14$ & 1,543 & 123,669 & 1.9 & $1.1-3.1$ \\
\hline & $15-17$ & 1,802 & 140,324 & 2.1 & $1.4-3.3$ \\
\hline \multirow[t]{2}{*}{ Male } & $12-14$ & 1,060 & 124,867 & 3.2 & $1.8-5.4$ \\
\hline & $15-17$ & 1,056 & 136,480 & 1.8 & $1.1-3.0$ \\
\hline Southeast & & 8,460 & $3,488,424$ & 2.4 & 1.9-3.0 \\
\hline \multirow[t]{2}{*}{ Female } & $12-14$ & 2,141 & 755,994 & 1.9 & $1.0-3.7$ \\
\hline & $15-17$ & 3,024 & 995,770 & 1.9 & $1.1-3.1$ \\
\hline \multirow[t]{2}{*}{ Male } & $12-14$ & 1,459 & 760,343 & 2.7 & $1.8-4.0$ \\
\hline & $15-17$ & 1,836 & 976,317 & 3.1 & $2.0-4.8$ \\
\hline South & & 4,690 & 821,105 & 3.5 & $2.6-4.9$ \\
\hline \multirow[t]{2}{*}{ Female } & $12-14$ & 1,157 & 186,354 & 5.7 & $2.5-12.7$ \\
\hline & $15-17$ & 1,538 & 226,094 & 2.1 & $1.0-4.3$ \\
\hline \multirow[t]{2}{*}{ Male } & $12-14$ & 879 & 188,266 & 1.6 & $0.9-2.8$ \\
\hline & $15-17$ & 1,116 & 220,391 & 4.8 & $3.3-6.9$ \\
\hline
\end{tabular}


from the sample are considered, the greatest MS prevalence was observed in the countryside cities of the South macro-region (4.1\% [95\%CI 2.8-5.9]).

The prevalence of MS was 2.8\% in public schools (95\%CI 2.4-3.2) and 1.9\% in private schools (95\%CI 1.4-2.4). In public schools, the prevalence of MS was 3.1\% in male adolescents (95\%CI 2.5-3.7) and 2.6\% in the females (95\% CI 2.0-3.3). In private schools, the prevalence was lower in both male (2.5\% [95\% CI 1.9-3.3]) and female adolescents (1.3\% [95\%CI 0.9-1.9]).

The prevalences of MS in adolescents with adequate nutritional status were less than $0.2 \%$, both in male (0.008\% [95\% CI 0.003-0.03]) and female (0.1\% [95\%CI 0.05-0.4]) adolescents. In the North, Northeast and Southeast regions the prevalence of MS in this group of adolescents was $0.1 \%$, and lower still in the Midwest and South regions.

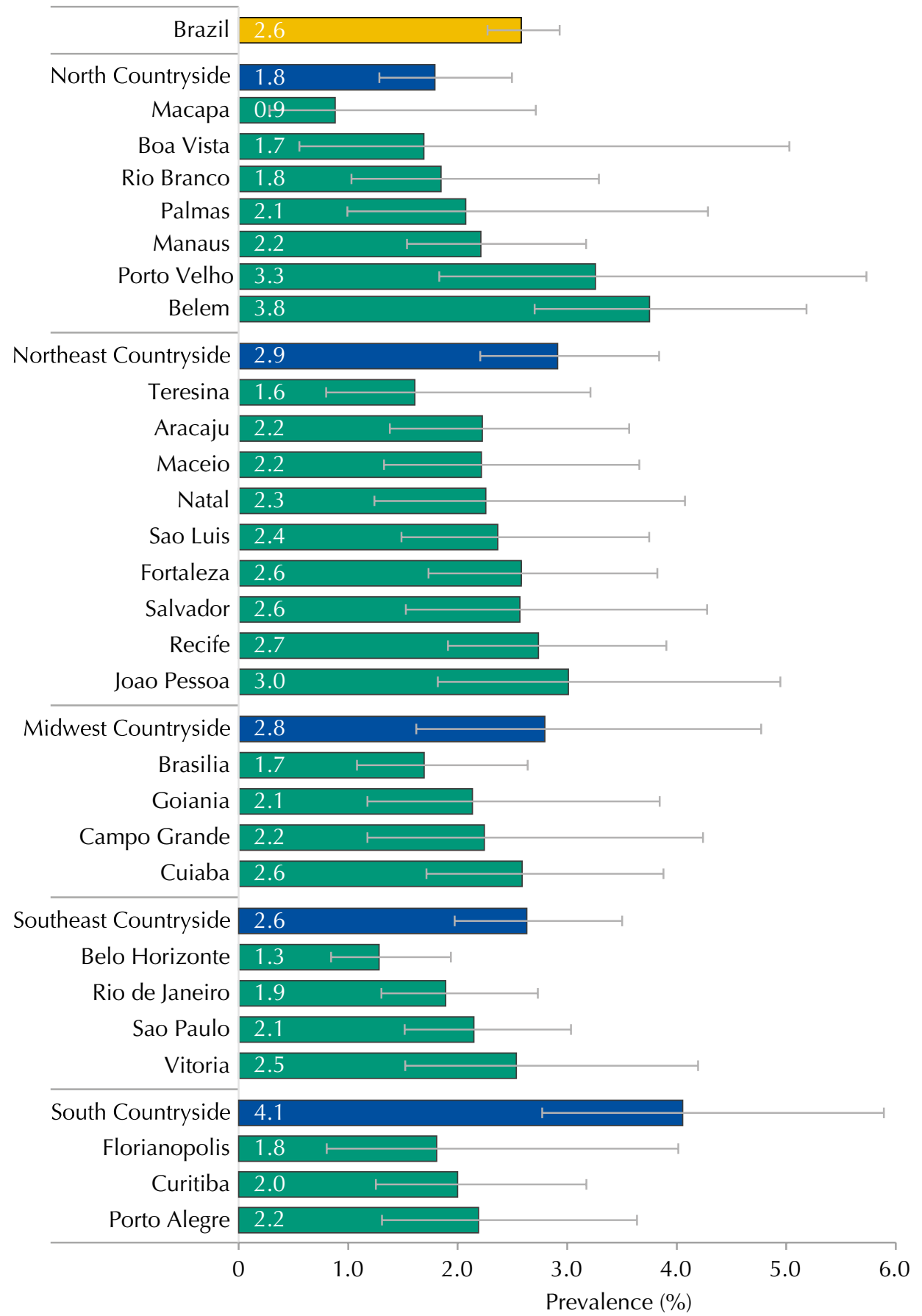

Figure 2. Prevalences (\%) and $95 \% \mathrm{Cl}$ of metabolic syndrome in adolescents according to strata of the capital and countryside regions. ERICA, Brazil, 2013-2014. 
Table 3. Prevalences (\%) and $95 \% \mathrm{Cl}$ of metabolic syndrome in overweight or obese adolescents, according to sex and macro-region. ERICA, Brazil, 2013-2014.

\begin{tabular}{lccccc}
\hline \multirow{2}{*}{ Regions/Sex } & \multicolumn{2}{c}{ Overweight } & & \multicolumn{2}{c}{ Obesity } \\
\cline { 2 - 3 } \cline { 5 - 6 } & $\%$ & $\mathbf{9 5 \%} \mathbf{C I}$ & & $\%$ & $\mathbf{9 5} \mathbf{C l}$ \\
\hline Brazil & 3.3 & $2.4-4.5$ & & 21.3 & $18.5-24.5$ \\
Female & 4.0 & $2.6-6.0$ & & 17.5 & $13.7-21.9$ \\
Male & 2.6 & $1.6-4.1$ & & 24.5 & $20.1-29.6$ \\
North & 3.3 & $2.4-4.4$ & & 24.7 & $20.5-29.5$ \\
Female & 5.1 & $3.6-7.1$ & & 22.4 & $16.6-29.5$ \\
Male & 1.3 & $0.7-2.6$ & & 26.3 & $20.1-33.6$ \\
Northeast & 3.3 & $2.1-5.3$ & & 21.7 & $16.7-27.8$ \\
Female & 3.5 & $2.2-5.6$ & & 20.1 & $12.2-31.2$ \\
Male & 3.1 & $1.7-5.7$ & & 22.8 & $17.9-28.6$ \\
Midwest & 2.1 & $1.2-3.0$ & & 21.7 & $16.1-27.9$ \\
Female & 3.1 & $1.9-5.1$ & & 23.9 & $16.2-33.8$ \\
Male & 1.2 & $0.5-2.4$ & & 20.5 & $14.8-27.7$ \\
Southeast & 3.9 & $2.4-6.2$ & & 18.9 & $14.5-24.2$ \\
Female & 4.8 & $2.5-9.1$ & & 11.3 & $7.8-16.0$ \\
Male & 3.0 & $1.4-6.1$ & & 26.1 & $17.9-36.4$ \\
South & 1.6 & $0.9-3.0$ & & 27.3 & $20.7-35.2$ \\
Female & 1.8 & $0.8-4.0$ & 31.8 & $19.4-47.5$ \\
Male & 1.4 & $0.6-3.4$ & 23.6 & $16.5-32.6$ \\
\hline
\end{tabular}

Table 4. Prevalences (\%) and $95 \% \mathrm{Cl}$ of metabolic syndrome in adolescents by sex, age and Brazilian regions according to nutritional status. ERICA, 2013-2014.

\begin{tabular}{|c|c|c|c|}
\hline Characteristic & Nutritional status & $\%$ & $95 \% \mathrm{Cl}$ \\
\hline \multirow[t]{3}{*}{ Brazil } & Eutrophic & 0.1 & $0.02-0.2$ \\
\hline & Overweight & 3.3 & $2.4-4.5$ \\
\hline & Obese & 21.3 & $18.5-24.5$ \\
\hline \multirow[t]{3}{*}{ Female } & Eutrophic & 0.1 & $0.03-0.4$ \\
\hline & Overweight & 4.0 & $2.6-6.0$ \\
\hline & Obese & 17.5 & $13.7-21.9$ \\
\hline \multirow[t]{3}{*}{ Male } & Eutrophic & 0.008 & $0.003-0.03$ \\
\hline & Overweight & 2.6 & $1.6-4.1$ \\
\hline & Obese & 24.5 & $20.1-29.6$ \\
\hline \multirow[t]{3}{*}{$12-14$ years } & Eutrophic & 0.01 & $0.006-0.04$ \\
\hline & Overweight & 1.7 & $0.7-3.8$ \\
\hline & Obese & 19.6 & $15.8-24.1$ \\
\hline \multirow[t]{3}{*}{$15-17$ years } & Eutrophic & 0.1 & $0.04-0.4$ \\
\hline & Overweight & 4.9 & $3.6-6.6$ \\
\hline & Obese & 23.5 & $19.1-28.6$ \\
\hline \multirow[t]{3}{*}{ North } & Eutrophic & 0.1 & $0.02-0.2$ \\
\hline & Overweight & 3.3 & $2.4-4.4$ \\
\hline & Obese & 24.7 & $20.5-29.5$ \\
\hline \multirow[t]{3}{*}{ Northeast } & Eutrophic & 0.1 & $0.03-0.2$ \\
\hline & Overweight & 3.3 & $2.1-5.3$ \\
\hline & Obese & 21.7 & $16.89-27.5$ \\
\hline \multirow[t]{3}{*}{ Midwest } & Eutrophic & 0.02 & $0.01-0.1$ \\
\hline & Overweight & 1.6 & $0.9-3.0$ \\
\hline & Obese & 27.3 & $20.7-35.2$ \\
\hline \multirow[t]{3}{*}{ Southeast } & Eutrophic & 0.02 & $0.0-0.1$ \\
\hline & Overweight & 2.1 & $1.4-3.2$ \\
\hline & Obese & 21.7 & $16.7-27.8$ \\
\hline \multirow[t]{3}{*}{ South } & Eutrophic & 0.1 & $0.01-0.4$ \\
\hline & Overweight & 3.9 & $2.5-6.2$ \\
\hline & Obese & 18.9 & $14.5-24.2$ \\
\hline
\end{tabular}



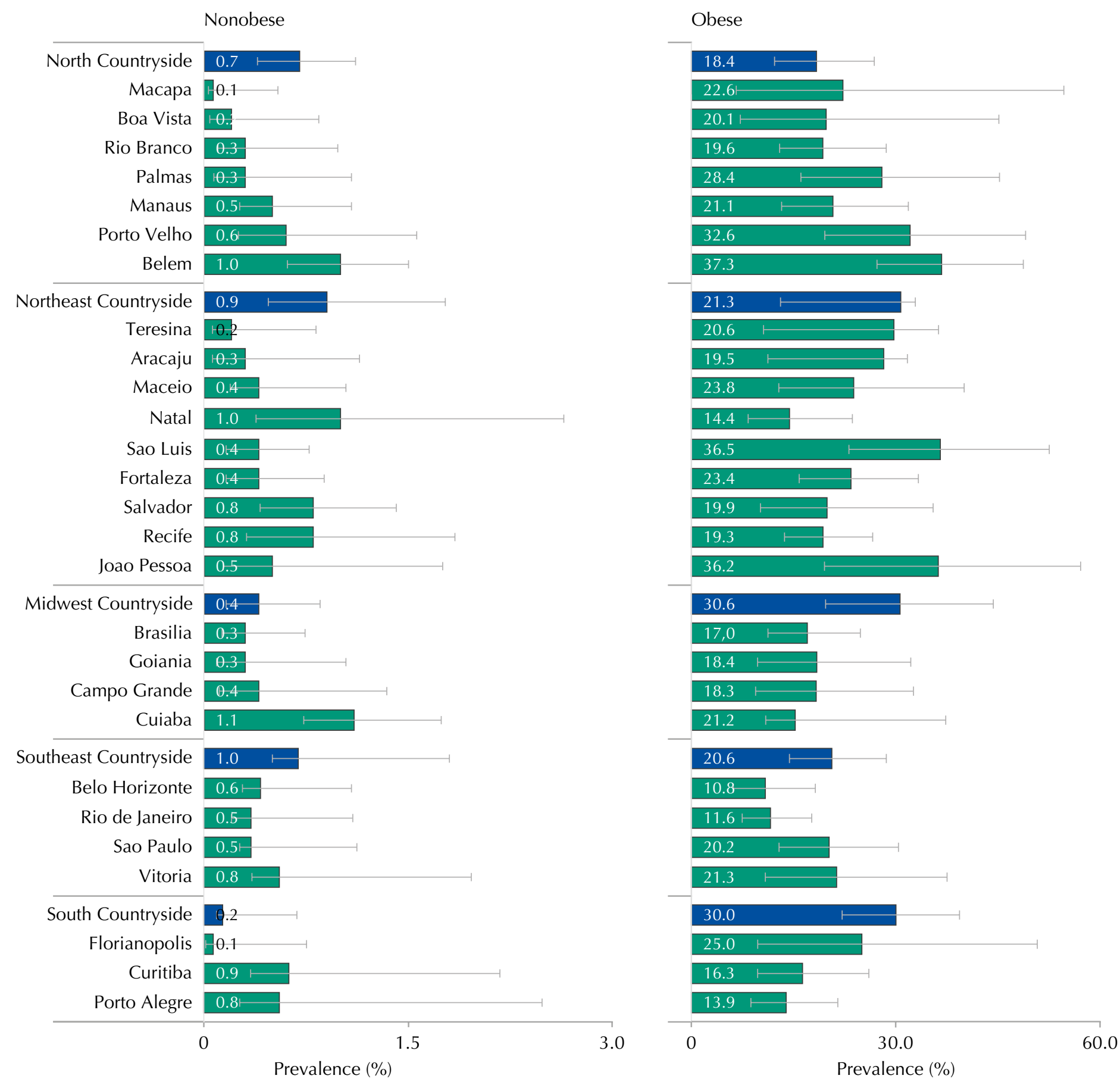

Figure 3. Prevalences (\%) and $95 \% \mathrm{Cl}$ of metabolic syndrome in obese and nonobese adolescents according to strata of the capital and countryside regions. ERICA, Brazil, 2013-2014. 
Table 5. Prevalences (\%) and $95 \% \mathrm{Cl}$ of metabolic syndrome in adolescents by capital and strata of the countryside regions. ERICA, Brazil, 2013-2014.

\begin{tabular}{|c|c|c|c|c|c|c|}
\hline \multirow{2}{*}{ Strata } & \multicolumn{2}{|c|}{ Total } & \multicolumn{2}{|c|}{ Nonobese } & \multicolumn{2}{|c|}{ Obese } \\
\hline & $\%$ & $95 \% \mathrm{Cl}$ & $\%$ & $95 \% \mathrm{Cl}$ & $\%$ & $95 \% \mathrm{Cl}$ \\
\hline North Countryside & 1.8 & $1.3-2.5$ & 0.7 & $0.4-1.1$ & 18.4 & $12.2-26.9$ \\
\hline Porto Velho & 3.3 & $1.8-5.7$ & 0.6 & $0.3-1.6$ & 32.6 & $19.6-49.0$ \\
\hline Rio Branco & 1.9 & $1.0-3.3$ & 0.3 & $0.1-1.0$ & 19.6 & $12.9-28.6$ \\
\hline Manaus & 2.2 & $1.5-3.2$ & 0.5 & $0.3-1.1$ & 21.1 & $13.2-31.8$ \\
\hline Boa Vista & 1.7 & $0.6-5.0$ & 0.2 & $0-0.8$ & 20.1 & $7.2-45.1$ \\
\hline Belem & 3.8 & $2.7-5.2$ & 1.0 & $0.6-1.5$ & 37.3 & $27.2-48.7$ \\
\hline Macapa & 0.9 & $0.3-2.7$ & 0.1 & $0-0.5$ & 22.6 & $6.6-54.6$ \\
\hline Palmas & 2.1 & $1.0-4.3$ & 0.3 & $0.1-1.1$ & 28.4 & $16.1-45.2$ \\
\hline Northeast Countryside & 2.9 & $2.2-3.8$ & 0.9 & $0.5-1.8$ & 21.3 & $13.0-32.9$ \\
\hline Sao Luis & 2.4 & $1.5-3.7$ & 0.4 & $0.2-0.8$ & 36.5 & $23.1-52.5$ \\
\hline Teresina & 1.6 & $0.8-3.2$ & 0.2 & $0.1-0.8$ & 20.6 & $10.6-36.3$ \\
\hline Fortaleza & 2.6 & $1.7-3.8$ & 0.4 & $0.2-0.9$ & 23.4 & $15.8-33.3$ \\
\hline Natal & 2.3 & $1.2-4.1$ & 1.0 & $0.4-2.6$ & 14.4 & $8.3-23.6$ \\
\hline Joao Pessoa & 3.0 & $1.8-4.9$ & 0.5 & $0.1-1.8$ & 36.2 & $19.5-57.1$ \\
\hline Recife & 2.7 & $1.9-3.9$ & 0.8 & $0.3-1.8$ & 19.3 & $13.7-26.6$ \\
\hline Maceio & 2.2 & $1.3-3.7$ & 0.4 & $0.2-1.0$ & 23.8 & $12.8-40.0$ \\
\hline Aracaju & 2.2 & $1.4-3.6$ & 0.3 & $0.1-1.1$ & 19.5 & $11.2-31.7$ \\
\hline Salvador & 2.6 & $1.5-4.3$ & 0.8 & $0.4-1.4$ & 19.9 & $10.1-35.5$ \\
\hline Midwest Countryside & 2.8 & $1.6-4.8$ & 0.4 & $0.2-0.9$ & 30.6 & $19.7-44.3$ \\
\hline Campo Grande & 2.2 & $1.2-4.2$ & 0.4 & $0.1-1.3$ & 18.3 & $9.4-32.6$ \\
\hline Cuiaba & 2.6 & $1.7-3.9$ & 1.1 & $0.7-1.7$ & 21.2 & $10.9-37.3$ \\
\hline Goiania & 2.1 & $1.2-3.8$ & 0.3 & $0.1-1.0$ & 18.4 & $9.7-32.2$ \\
\hline Brasilia & 1.7 & $1.1-2.6$ & 0.3 & $0.1-0.7$ & 17.0 & $11.2-24.8$ \\
\hline Southeast Countryside & 2.6 & $2.0-3.5$ & 1.0 & $0.5-1.8$ & 20.6 & $14.4-28.6$ \\
\hline Belo Horizonte & 1.3 & 0.8-1.9 & 0.6 & $0.3-1.1$ & 10.8 & $6.2-18.2$ \\
\hline Vitoria & 2.5 & $1.5-4.2$ & 0.8 & $0.3-2.0$ & 21.3 & $10.8-37.5$ \\
\hline Rio de Janeiro & 1.9 & $1.3-2.7$ & 0.5 & $0.2-1.1$ & 11.6 & $7.5-17.7$ \\
\hline Sao Paulo & 2.1 & $1.5-3.0$ & 0.5 & $0.3-1.1$ & 20.2 & $12.9-30.4$ \\
\hline South Countryside & 4.1 & $2.8-5.9$ & 0.2 & $0.1-0.7$ & 30.0 & $22.1-39.3$ \\
\hline Curitiba & 2.0 & $1.3-3.2$ & 0.9 & $0.3-2.2$ & 16.3 & $9.7-26.0$ \\
\hline Florianopolis & 1.8 & $0.8-4.0$ & 0.1 & $0.0-0.7$ & 25.0 & $9.7-50.7$ \\
\hline Porto Alegre & 2.2 & $1.3-3.6$ & 0.8 & $0.3-2.5$ & 13.9 & $8.7-21.5$ \\
\hline
\end{tabular}

Regarding the composition of the MS, which according to the adopted criteria must include the presence of enlarged WC, $82.3 \%$ (95\%CI 79.2-85.0) of the adolescents with MS were observed to present three components, $15.6 \%$ (95\%CI 13.0-18.6) had four components, and $2.1 \%$ (95\% CI 1.0-4.5) had five components.

The most frequently observed MS component combinations were: enlarged WC, low HDL-c and high blood pressure at 33.4\%; enlarged WC, low HDL-c and high triglycerides at 31.8\%; and enlarged WC, low HDL-c and high triglycerides and blood pressure at 9.5\%. These combinations of factors represented about $3 / 4$ of all possible combinations.

Table 6 describes the prevalence of MS components throughout the sample, the prevalence of MS in those with each of the components and the prevalence of each component in adolescents with MS. About 1/3 of the adolescents had low HDL-c, which was reflected in the high prevalence of this component among adolescents with MS; however, less than $10.0 \%$ of adolescents with this variation had MS. Concerning high triglycerides, despite having 
Table 6. Prevalence (\%) and $95 \% \mathrm{Cl}$ of MS components in the population, of MS in adolescents with particular components, and of components in adolescents with MS. ERICA, Brazil, 2013-2014.

\begin{tabular}{|c|c|c|c|c|c|}
\hline \multirow[t]{2}{*}{ MS components } & \multicolumn{2}{|c|}{$\begin{array}{l}\text { Prevalence of the } \\
\text { component }\end{array}$} & \multicolumn{2}{|c|}{$\begin{array}{l}\text { Prevalence of MS in } \\
\text { adolescents with the } \\
\text { component }\end{array}$} & \multirow{2}{*}{$\begin{array}{c}\text { Prevalence of } \\
\text { the component } \\
\text { in adolescents } \\
\text { with MS } \\
\% \\
\end{array}$} \\
\hline & $\%$ & $95 \% \mathrm{CI}$ & $\%$ & $95 \% \mathrm{Cl}$ & \\
\hline$W C^{a}$ & 12.6 & $11.6-13.7$ & 20.5 & $18.2-22.9$ & 100 \\
\hline HDL-c ${ }^{b}$ & 32.7 & $30.3-35.2$ & 7.2 & $6.3-8.2$ & 90.7 \\
\hline Triglycerides $^{\mathrm{a}}$ & 4.6 & $4.1-5.1$ & 26.8 & $22.4-31.7$ & 47.6 \\
\hline Glucose $^{\mathrm{a}}$ & 4.1 & $3.5-4.8$ & 15.0 & $10.8-20.4$ & 20.6 \\
\hline Blood pressure & 8.2 & $7.6-8.9$ & 18.7 & $15.6-22.1$ & 57.6 \\
\hline
\end{tabular}

MS: metabolic syndrome; WC: waist circumference; HDL-c: HDL-cholesterol a High.

${ }^{b}$ Low.

been presented at a low prevalence compared to the other components in the total sample, they were present in almost half of all the adolescents with MS; and the prevalence of MS in those with this variation was high $(26.8 \%)$, even greater than in those with the required component, i.e., enlarged WC (20.5\%). High glucose levels, which had the lowest prevalence of all the components in the total sample, was associated with MS prevalence of around two times greater than in the presence of low HDL-c. Nearly $20.0 \%$ of adolescents with high blood pressure, according to the IDF criteria, were classified as having MS; and among the adolescents with MS, just over half had high blood pressure (Table 6).

\section{DISCUSSION}

This was the first study performed with a representative sample of the Brazilian population, in this age group, in which important information is shown regarding the prevalence of MS. The observed prevalences varied according to the macro-region, sex and age without presenting any specific single pattern. The prevalence of MS in the South region was greater than in the other regions, mostly due to the prevalence observed in the cities with more than 100,000 inhabitants in the countryside of this macro-region. This fact can be attributed to different eating habits and lifestyles in relation to the macro-regions, since these are the main factors in the genesis of obesity, which is a central component in MS diagnosis.

We observed higher prevalence of MS in adolescents from public schools, which indicates a possible association between socioeconomic factors and MS. Analyzing the characteristics that may vary according to socioeconomic status, such as parenting, eating habits or physical activities, can help in the understanding of these relationships. Some studies observed an opposite relationship to what was found in ERICA, i.e., a greater prevalence of MS in higher income individuals $\mathrm{s}^{5,7,8}$.

More than 40 MS definitions for children and adolescents exist ${ }^{11}$. The MS definition proposed by the IDF puts forward prevalences that tend to be lower than those estimated with other definitions of frequent use. Some studies with smaller proportions than those with ERICA, such as Alvarez et al. ${ }^{1}$, who evaluated 577 adolescents from public and private schools in the Brazilian city of Niteroi, RJ, Southeastern Brazil, observed an MS prevalence of $1.6 \%$ (95\%CI 0.6-3.9) using the IDF definition and 6.0\% (95\%CI 3.0-7.8) using the NCEP-ATPIII criteria. This difference may have been due to the required presence of enlarged WC in the IDF definition.

No consensus exists regarding the most suitable criteria, and adolescents represent a fraction of the population, whose main characteristic is defined by transformation. Therefore, using a more specific definition (not labeling those with a low probability of having this 
syndrome or their false-positives as MS patients) seems more appropriate than using a more sensitive criterion.

During ERICA, the prevalence of MS among the obese only differed in terms of sex in the North and Southeast regions. In the North, it was higher among female overweight adolescents; and in the Southeast, it was obese males. Most research projects report a higher prevalence in male adolescents ${ }^{21,23}$.

While using data on adolescents from the National Health and Nutrition Examination Survey (NHANES), Laurson et al. ${ }^{13}$ noted, in accordance with the NCEP-ATPIII criteria, an $0.8 \%$ prevalence of MS in 1,785 male adolescents with adequate nutritional status (95\% CI 0.1-1.5), $6.8 \%$ in overweight individuals (95\%CI 1.2-12.4) and 35.4\% in the obese (95\% CI 27.1-43.7). In 1,600 female adolescents, we observed MS prevalence of $1.7 \%$ for individuals who were neither overweight or obese (95\% CI 0.1-3.3), 9.2\% for overweight females (95\%CI 4.4-14.0) and $24.6 \%$ for the obese (95\%CI 17.2-31.9). In this study, the prevalence of MS was lesser in both male and female adolescents, regardless of nutritional status, when compared to the prevalence found in the study by Laurson et al., albeit with different criteria employed. Nasreddine et al. ${ }^{16}$, while using the IDF criteria, observed a prevalence of $21.2 \%$ in obese Lebanese adolescents, $3.8 \%$ in the overweight and $1.2 \%$ in individuals who were neither overweight or obese, which are similar results to those observed during ERICA.

In this study, the prevalence of the MS components, observed in adolescents with MS, in descending order, were: enlarged WC, low HDL-c, high triglycerides, blood pressure and glucose levels. Nasreddine et al. ${ }^{16}$ observed a similar descending order. However, analyzing the contribution of each MS component enables the visualization of the importance of the individualized model. Despite the prevalence of low HDL-c having been singularly the highest, the prevalence of MS was higher in adolescents with high triglycerides or high blood pressure. In other words, according to the IDF criteria, the triglycerides represented a relevant component.

MS is directly associated with insulin resistance and it is this that enables the promotion and explanation of the emergence, prevalence and magnitude of each of the MS components ${ }^{3,14,19}$. The presence of only one of the MS components supports non-medicinal interventions, such as promoting healthy lifestyle habits, in addition to follow-up at health services. Despite the MS prevalences having been low during ERICA, we observed a strong association with nutritional status, which indicates that preventing obesity can have a significant impact on reducing MS prevalence as well as its subsequent cardiovascular complications during adult life.

\section{REFERENCES}

1. Alvarez MM, Vieira ACR, Sichieri R, Veiga GV. Prevalence of metabolic syndrome and of its specific components among adolescents from Niterói City, Rio de Janeiro State, Brazil. Arq Bras Endocrinol Metab. 2011;55(2):164-70. DOI:10.1590/S0004-27302011000200009

2. American Diabetes Association. Diagnosis and classification of diabetes mellitus. Diabetes Care. 2010;33 Suppl 1:S62-9. DOI:10.2337/dc10-S062

3. Barter P. HDL-C: role as a risk modifier. Atheroscler Suppl. 2011;12(3):267-70. DOI:10.1016/S1567-5688(11)70885-6

4. Bloch KV, Szklo M, Kuschnir MCC, Abreu GA, Barufaldi LA, Klein CH et al. The Study of Cardiovascular Risk in Adolescents - ERICA: rationale, design and sample characteristics of a national survey examining cardiovascular risk factor profile in Brazilian adolescents. BMC Public Health. 2015;15:94-103. DOI:10.1186/s12889-015-1442-x

5. Buff CG, Ramos E, Souza FIS, Sarni ROS. Frequência de síndrome metabólica em crianças e adolescentes com sobrepeso e obesidade. Rev Paul Pediatr. 2007;25(3):221-6. DOI:10.1590/S0103-05822007000300005 
6. Castro IRR, Cardoso LO, Engstrom EM, Levy RB, Monteiro CA. Vigilância de fatores de risco para doenças não transmissíveis entre adolescentes: a experiência da cidade do Rio de Janeiro, Brasil. Cad Saude Publica. 2008;24(10):2279-88. DOI:10.1590/S0102-311X2008001000009

7. Christofaro DGD, Andrade SM, Fernandes RA, Ohara D, Dias DF, Freitas Jr IF et al. Prevalência de fatores de risco para doenças cardiovasculares entre escolares em Londrina - PR: diferenças entre classes econômicas. Rev Bras Epidemiol. 2011;14(1):27-35. DOI:10.1590/S1415-790X2011000100003

8. Cook S, Weitzman M, Auinger P, Nguyen M, Dietz WH. Prevalence of a metabolic syndrome phenotype in adolescents: findings from the Third National Health and Nutrition Examination Survey, 1988-1994. Arch Pediatr Adolesc Med. 2003;157(8):821-7. DOI:10.1001/archpedi.157.8.821

9. Fernández JR, Redden DT, Pietrobelli A, Allison DB. Waist circumference percentiles in nationally representative samples of African-American, European-American and Mexican-American children and adolescents. J Pediatr. 2004;145(4):439-44. DOI:10.1016/j.jpeds.2004.06.044

10. Ferranti SD, Gauvreau K, Ludwig DS, Neufeld EJ, Newburger JW, Rifai N. Prevalence of the metabolic syndrome in American adolescents: findings from The Third National Health and Nutrition Examination Survey. Circulation. 2004;110(16): 2494-7. DOI:10.1161/01.CIR0000145117.40114.C7

11. Ford ES, Li C. Defining the metabolic syndrome in children and adolescents: will the real definition please stand up? J Pediatr. 2008;152(2):160-4. DOI:10.1016/j.jpeds.2007.07.056

12. Giannini DT, Kuschnir MCC, Szklo M. Metabolic syndrome in overweight and obese adolescents: a comparison of two different diagnostic criteria. Ann Nutr Metab. 2014;6(1):71-9. DOI:10.1159/000362568

13. Laurson KR, Welk GJ, Eisenmann JC. Diagnostic performance of BMI percentiles to identify adolescents with metabolic syndrome. Pediatrics. 2014;133(2):e330-8. DOI:10.1542/peds.2013-1308

14. Miller M, Stone NJ, Ballantyne C, Bittner V, Criqui MH, Ginsberg HN et al. Triglycerides and cardiovascular disease: a scientific statement from the American Heart Association. Circulation. 2011;123(20):2292-333. DOI:10.1161/CIR.0b013e3182160726

15. Muoio DM, Newgard CB. Mechanisms of disease: molecular and metabolic mechanisms of insulin resistance and beta-cell failure in type 2 diabetes. Nat Rev Mol Cell Biol. 2008;9(3):193-205. DOI:10.1038/nrm2327

16. Nasreddine L, Naja F, Tabet M, Habbal MZ, El-Aily A, Haikal C et al. Obesity is associated with insulin resistance and components of the metabolic syndrome in Lebanese adolescents. Ann Hum Biol. 2012;39(2):122-8. DOI:10.3109/03014460.2012.655776

17. Onis M, Onyango AW, Borghi E, Siyam A, Nishida C, Siekemann J. Development of a WHO growth reference for school-aged children and adolescents. Bull World Health Organ. 2007;85(9):660-7. DOI:10.2471/BLT.07.043497

18. Onis M, Blössner M, Borghi E. Global prevalence and trends of overweight and obesity among preschool children. Am J Clin Nutr. 2010;92(5):1257-64. DOI:10.3945/ajcn.2010.29786

19. Reaven GM. Banting lecture 1988. Role of insulin resistance in human disease. Diabetes. 1988;37(12):1595-607. DOI:10.2337/diab.37.12.1595

20. Sociedade Brasileira de Cardiologia, Departamento de Aterosclerose, et al. I Diretriz de Prevenção da Aterosclerose na Infância e na Adolescência. Arq Bras Cardiol. 2005;85 Supl 6:3-36. DOI:10.1590/S0066-782X2005002500001

21. Stergiou GS, Yiannes NG, Rarra VC. Validation of the Omron 705 IT oscillometric device for home blood pressure measurement in children and adolescents: the Arsakion School Study. Blood Press Monit. 2006;11(4):229-34. DOI:10.1097/01.mbp.0000209074.38331.16

22. Tavares LF, Yokoo EM, Rosa MLG, Fonseca SC. Síndrome metabólica em crianças e adolescentes: revisão sistemática. Cad Saude Coletiva. 2010;18(4):469-76.

23. Vasconcellos MTL, Silva PLN, Szklo M, Kuschnir MCC, Klein CH, Abreu GA et al. Desenho da amostra do Estudo do Risco Cardiovascular em Adolescentes (ERICA). Cad Saude Publica. 2015;31(5):921-30. DOI:10.1590/0102-311X00043214

24. Wang J, Zhu Y, Cai L, Jing J, Chen Y, Mai J et al. Metabolic syndrome and its associated early-life factors in children and adolescents: a cross-sectional study in Guangzhou, China. Public Health Nutr. 2015;8:1-8. DOI:10.1017/S1368980015002542 
25. Zimmet P, Alberti K, Kaufman F, Tajima N, Silink M, Arslanian S et al. The metabolic syndrome in children and adolescents. Lancet. 2007;369(9579):2059-61. DOI:10.1016/S0140-6736(07)60958-1

*Complementary List of the Authors: Ana Júlia Pantoja de Moraes (Instituto Ciências da Saúde. Universidade Federal do Pará. Belém, PA, Brasil); Ana Luíza Borges (Departamento de Enfermagem em Saúde Coletiva, Universidade de São Paulo. São Paulo, SP, Brasil); Ana Mayra Andrade de Oliveira (Departamento de Saúde. Universidade Estadual de Feira de Santana. Feira de Santana, BA, Brasil); Bruno Mendes Tavares (Instituto de Saúde e Biotecnologia. Universidade Federal do Amazonas. Manaus, AM, Brasil); Cecília Lacroix de Oliveira (Departamento de Nutrição. Universidade do Estado do Rio de Janeiro. Rio de Janeiro, RJ, Brasil); Cristiane de Freitas Cunha (Hospital de Clínicas. Universidade Federal de Minas Gerais. Belo Horizonte, MG, Brasil); Denise Tavares Giannini (Centro Biomédico. Instituto de Nutrição. Universidade do Estado do Rio de Janeiro. Rio de Janeiro, RJ, Brasil); Dilson Rodrigues Belfort (Universidade Federal do Amapá. Macapá, AP, Brasil); Eduardo Lima Santos (Instituto Federal de Educação, Ciência e Tecnologia do Tocantins. Palmas, TO, Brasil); Elisa Brosina de Leon (Faculdade de Educação Física e Fisioterapia. Universidade Federal do Amazonas. Manaus, AM, Brasil); Elizabete Regina Araújo Oliveira (Departamento de Enfermagem. Universidade Federal do Espirito Santo. Vitória, ES, Brasil); Elizabeth Fujimori (Departamento de Enfermagem em Saúde Coletiva, Universidade de São Paulo. São Paulo, SP, Brasil); Erika da Silva Magliano (Instituto de Estudos em Saúde Coletiva. Universidade Federal do Rio de Janeiro. Rio de Janeiro, RJ, Brasil); Francisco de Assis Guedes Vasconcelos (Centro de Ciências da Saúde. Departamento de Nutrição. Universidade Federal de Santa Catarina. Florianópolis, SC, Brasil); George Dantas Azevedo (Centro de Biociências. Departamento de Morfologia. Universidade Federal do Rio Grande do Norte. Natal, RN, Brasil); Gisela Soares Brunken (Instituto de Saúde Coletiva. Departamento de Saúde Coletiva. Universidade Federal de Mato Grosso. Cuiabá, MT, Brasil); Isabel Cristina Britto Guimarães (Hospital Ana Neri. Universidade Federal da Bahia. Salvador, BA, Brasil); José Rocha Faria Neto (Escola de Medicina. Pontifícia Universidade Católica do Paraná. Curitiba, PR, Brasil); Juliana Souza Oliveira (Centro Acadêmico de Vitória. Universidade Federal de Pernambuco. Recife, PE, Brasil); Kenia Mara B de Carvalho (Departamento de Nutrição. Universidade de Brasília. Brasília, DF, Brasil); Luis Gonzaga de Oliveira Gonçalves (Núcleo de Saúde. Departamento de Educação Física. Universidade Federal de Rondônia. Porto Velho, RO, Brasil); Maria Inês Monteiro (Faculdade de Enfermagem. Universidade Estadual de Campinas. Campinas, SP, Brasil); Marize M Santos (Centro de Ciências da Saúde. Departamento de Nutrição. Universidade Federal do Piauí. Teresina, PI, Brasil); Pascoal Torres Muniz (Departamento de Ciências da Saúde e Educação Física. Universidade Federal do Acre. Rio Branco, AC, Brasil); Paulo César B Veiga Jardim (Faculdade de Medicina. Universidade Federal de Goiás. Goiânia, GO, Brasil); Pedro Antônio Muniz Ferreira (Programa de Pós-Graduação em Saúde Coletiva. Universidade Federal do Maranhão. São Luís, MA, Brasil); Renan Magalhães Montenegro Jr (Faculdade de Medicina. Departamento de Saúde Comunitária. Universidade Federal do Ceará. Fortaleza, CE, Brasil); Ricardo Queiroz Gurgel (Centro de Ciências Biológicas e da Saúde. Departamento de Medicina. Universidade Federal de Sergipe. Aracajú, SE, Brasil); Rodrigo Pinheiro Vianna (Centro de Ciências da Saúde. Departamento de Nutrição. Universidade Federal da Paraíba. João Pessoa, PB, Brasil); Sandra Mary Vasconcelos (Departamento de Nutrição. Universidade Federal de Alagoas. Maceió, AL, Brasil); Stella Maris Seixas Martins (Centro de Ciências da Saúde. Universidade Federal de Roraima. Boa Vista, RR, Brasil); Tamara Beres Lederer Goldberg (Faculdade de Medicina de Botucatu. Departamento de Pediatria. Universidade Estadual Paulista Júlio Mesquita Filho. Botucatu, SP, Brasil).

Funding: Department of Science and Technology of the Secretariat of Science, Technology and Strategic Inputs of the Ministry of Health (Decit/SCTIE/MS) and by the Health Sectorial Fund (Fundo Setorial de Saúde - CT-Saúde) of the Ministry of Science, Technology and Innovation (MCTI). Protocols: FINEP (01090421), CNPq (2010/565037-2) and Research Incentive Fund of the Hospital de Clínicas de Porto Alegre - (Fundo de Incentivo à Pesquisa do Hospital de Clínicas de Porto Alegre - FIPE-HCPA) (405.009/2012-7).

Authors' Contribution: Study coordination, design and drafting of the article: MCCK, KBV. Coordination and design: MS. Data analysis: CHK, TLNS, BMT. Data coordination and analysis: LAB, GAA. Bibliographic search: GVV, BS. Sample calculation: MTLV. Data collection: ANPM, ALB, AMAO, CLO, CFC, DTG, DLBR, ELS, EBL, EF, ERAO, ESM, FAGV, GDA, GSB, ICBG, JRFN, JSO, KMBC, LGOG, MIM, MMS, PTM, PCBVJ, PAMF, RMMJr, RQG, VPN, SMV, SMSM and TBLG. All authors participated in the critical review.

Acknowledgements: To the Brazilian Institute of Geography and Statistics (IBGE) for providing the electronic data collectors, the PDA (personal digital assistant), and to the Fundação Universitária José Bonifácio (FUJB), for managing the study's resources.

Conflict of Interest: The authors declare no conflict of interest. 


\section{RSP \\ Revista de \\ Saúde Pública}

http://www.rsp.fsp.usp.br/

In article: "ERICA: prevalence of metabolic syndrome in Brazilian adolescents", DOI:10.1590/S01518-8787.2016050006701, published in the journal "Revista de Saúde Pública", volume 50 (2016), supplement ERICA, article 11s.

\section{Where you read:}

How to cite: Kyscgubur NCC, Bloch KV, Szklo M, Klein CH, Barufaldi LA, Abreu GA et al. ERICA: prevalência de síndrome metabólica em adolescentes brasileiros. Rev Saude Publica. 2016;50(supl 1):11s.

\section{You should read:}

How to cite: Kuschnir MCC, Bloch KV, Szklo M, Klein CH, Barufaldi LA, Abreu GA et al. ERICA: prevalência de síndrome metabólica em adolescentes brasileiros. Rev Saude Publica. 2016;50(supl 1):11s. 